\title{
Presenting the 2019 TMS Scholars
}
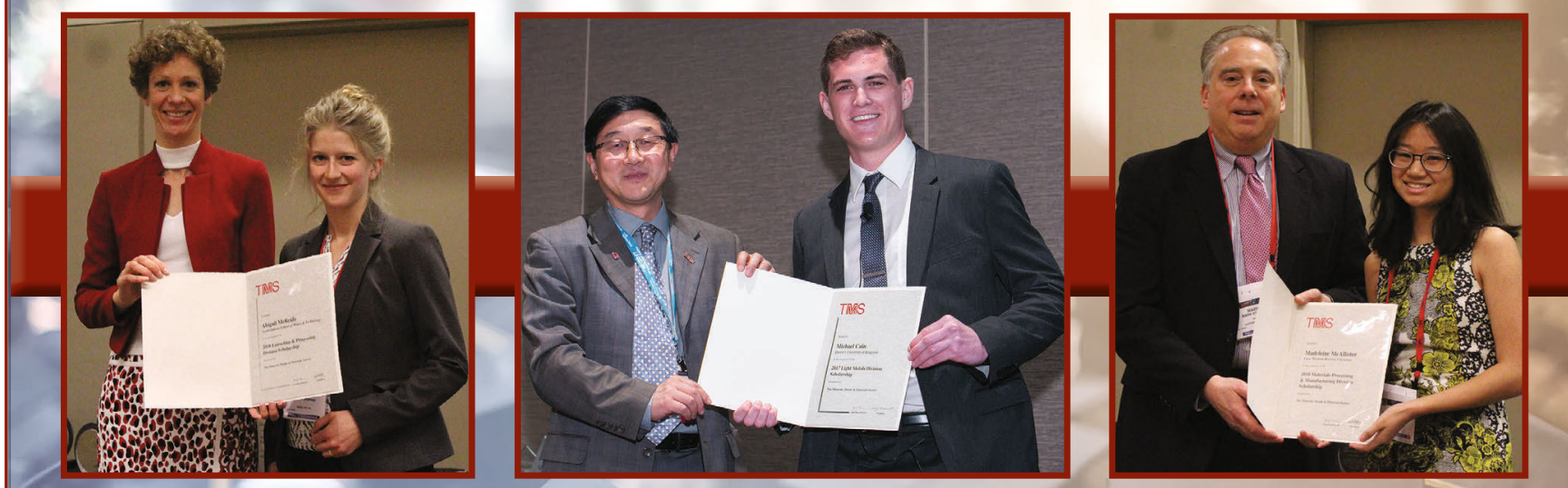

Ashley-Anne Bohnert and Carol Matty

Each year, a group of promising young students is honored by being named TMS scholarship recipients. This recognition is a validation of their commitment to their studies and helps lighten the burdens of student life through tuition assistance.

Another important aspect of this honor is the travel support provided for students to accept their awards at the TMS 2019 Annual Meeting \& Exhibition (TMS2019). Attending a TMS meeting gives these young scholars the opportunity to participate in inspiring and enlightening technical sessions, learn from leading figures in their fields of study, network with their peers, and establish connections with potential mentors.

Many of the students highlighted in these pages will accept their awards at their respective division functions or during the TMS-AIME Awards Ceremony held during TMS2019 in San Antonio, Texas, from March 10-14, 2019. The awards and lecture portions of division luncheons, as well as the TMS-AIME Awards Ceremony, are open to all TMS2019 registrants. Please plan to attend and show your support to the 2019 class of TMS Scholars.

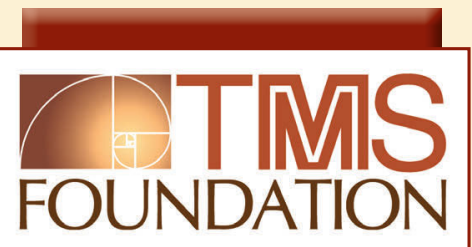

$$
4
$$

\section{Make a Difference through the TMS Foundation: Support the 2018 Year-End Appeal}

Each scholarship highlighted in this article is made possible through donations from individuals who want to ensure a bright future for the minerals, metals, and materials community. Please consider joining them to ensure that the TMS Foundation can continue its good work supporting scholarships, awards, and leadership development at every stage of the academic and professional career.

Beginning with the 2018 year-end appeal, donors now have the option to set up a recurring monthly gift of at least $\$ 10$ per month for 12 months that will help support the important initiatives of the TMS Foundation.

Visit www.TMSFoundation.org/Contribute to set up a monthly gift or to make a one-time donation online. You can also make a contribution by check, made payable to the TMS Foundation and mailed to TMS, 5700 Corporate Drive Suite 750, Pittsburgh, PA 15237. For more information or to discuss a donation personally, contact TMS Foundation staff at TMSFoundation@ tms.org.

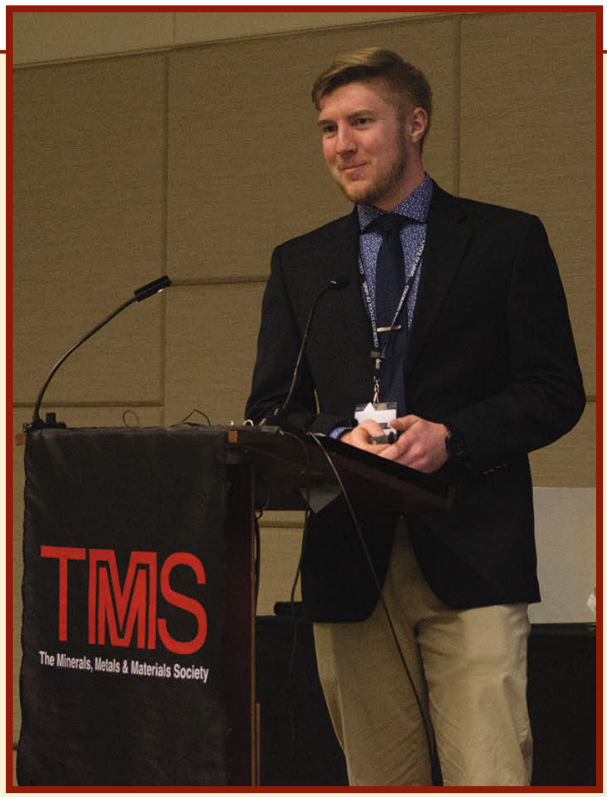

Nicholas Lipski, Colorado School of Mines and 2018 Light Metals Division (LMD)

Scholar, delivers a lecture during the LMD Luncheon at the TMS 2018 Annual Meeting \& Exhibition. His talk was entitled "Opportunities in Lightweight Metals - from Aluminum to High Entropy Alloys." 


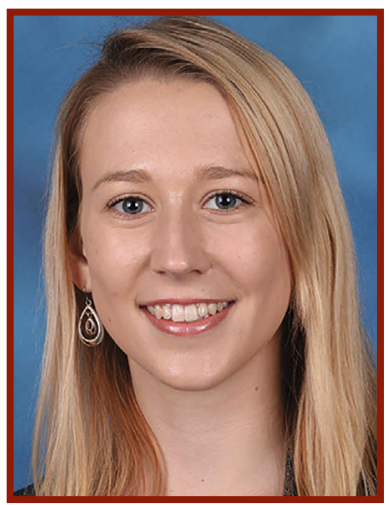

Brooklyn Carlson

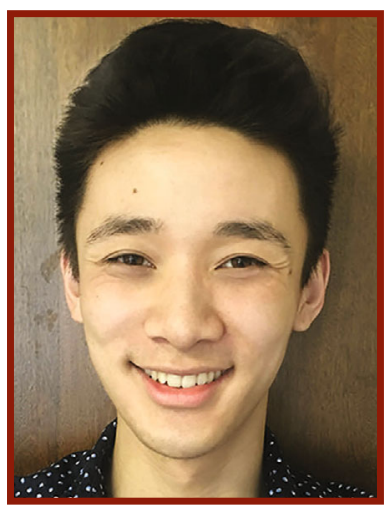

Justin Qian

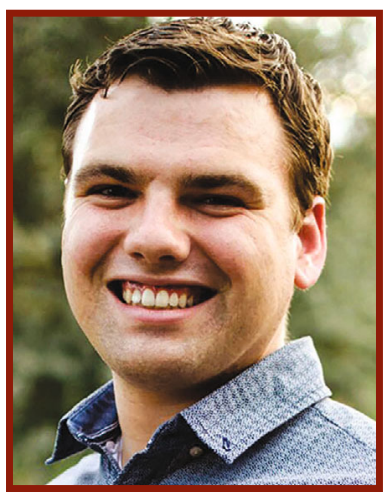

Tanner Livingston

\section{TMS DIVISION AWARDS}

TMS Division Scholarships Recipients will also receive a dollar-for-dollar scholarship match through the Battelle Matching Scholarship Program. This is made possible through the generous support of Battelle and its retired chief executive officer, Jeffrey Wadsworth.

Additionally, students who receive a Battelle Matching Scholarship will be eligible for a Battelle Materials Graduate Student Award when they matriculate to a graduate school to continue studies in a materials-related field.

\section{EXTRACTION \& PROCESSING DIVISION (EPD) SCHOLARSHIP}

Awarded through the EPD and the TMS Foundation to sophomore or junior undergraduate students majoring in the extracting and processing of minerals, metals, and materials.

\section{Brooklyn Carlson}

University of Wisconsin

"When I began my education in materials science and engineering, I was undecided which materials to focus on within my academic studies; however, the information made available as a student member of Material Advantage and TMS presented the opportunity to research the applications and industries related to materials engineering. With vast amounts of information at my disposal, I eventually decided to emphasize metals and polymers during my undergraduate education. With an anticipated graduation date of May 2019, I am in the process of searching for full-time employment in either the automotive, defense or aerospace industry, particularly in a manufacturing capacity."

\section{FUNCTIONAL MATERIALS DIVISION (FMD) GILBERT CHIN SCHOLARSHIP}

Awarded through the FMD and the TMS Foundation to sophomore or junior undergraduate students studying subjects related to synthesis and processing, structure, properties, and performance of electronic, photonic, magnetic, and superconducting materials, as well as materials used in packaging and interconnecting such materials in device structures.

\section{Justin Qian \\ University of Pennsylvania}

"I am very honored to receive the FMD Gilbert Chin Scholarship. I also extend my thanks to Battelle and Jeffrey Wadsworth for their matching and graduate scholarships. TMS and Material Advantage have been very helpful to my professional development by providing me with financial support, and also by giving me opportunities to interact with other professionals and students within materials science. My future plans include applying to graduate school to work on materials research. The support from TMS has been very helpful to me so far, and I hope to be able to contribute to the field in the future."

\section{LIGHT METALS DIVISION (LMD) SCHOLARSHIP}

Awarded through the LMD and the TMS Foundation to outstanding sophomore or junior undergraduate students majoring in metallurgical and/or materials science and engineering with an emphasis on both traditional and emerging light metals.

\section{Tanner Livingston \\ University of Utah}

"As a member of Material Advantage, I have many opportunities to meet with people in the metallurgical engineering industry. This is crucial in building connections for the future, and something I plan to continue doing as I near graduation. In particular, I am honored to have been allowed to apply for, and receive, this scholarship. The TMS LMD Scholarship will allow me to attend school without the stress of heavy student debt. This in turn allows me to focus more time on my family (wife and daughter), my studies, and my research." 


\section{MATERIALS PROCESSING \& MANUFACTURING DIVISION (MPMD) SCHOLARSHIPS}

Awarded through the MPMD and the TMS Foundation to sophomore or junior undergraduate students majoring in metallurgical and/or materials science and engineering, with an emphasis on manufacturing, integrating process control technology into manufacturing, and basic and applied research into key materials technologies that impact manufacturing processes.

\section{Mackenzie Keefer}

\section{Michigan Technological University}

"TMS has helped to provide resources and experiences that grant me a broader view of the ways my field of study can be applied. My most notable experience was attending the 2017 Materials Science and Technology (MS\&T) conference and participating in the presentation competition. This was a great opportunity to see the amazing materials science and engineering work that is being done, and to practice public speaking. Going forward I will be applying for full time positions in materials and processes groups in the Pacific Northwest, preferably in the aerospace industry."

\section{Matthew Thomas}

\section{Michigan Technological University}

"As a materials science and engineering student, it is an honor to be recognized by TMS and receive the MPMD Scholarship. This scholarship will provide me financial flexibility so that I may focus on my degree during my senior year at Michigan Technological University. After graduation, I plan on entering either the heat treatment or medical equipment production industry and then continuing on to higher education."

\section{SOCIETY AWARDS}

\section{KAUFMAN CALPHAD SCHOLARSHIP}

Awarded through CALPHAD Inc. and the TMS Foundation to sophomore or junior undergraduate students majoring in metallurgical engineering, materials science and engineering, or minerals processing/extraction programs. This scholarship was established to recognize the memory of Larry Kaufman for his contributions to computational thermodynamics and its applications.

\section{Katelyn Adkison}

Pennsylvania State University

"I am very honored to receive the Kaufman CALPHAD Scholarship. It will help me pay for my studies at Pennsylvania State University, a place that has provided a wealth of opportunities in research, classes, and clubs over the last three years. In addition, TMS and Material Advantage have allowed me to attend conferences where I was introduced to the diverse field of materials science through topics presented by other students and professionals. What I have learned from these experiences will help me succeed in a career in the metals or biomaterials industry after graduation."

\section{TMS INTERNATIONAL SYMPOSIUM ON \\ SUPERALLOYS SCHOLARSHIP}

This award is for undergraduate and graduate students majoring in metallurgical and/or materials science and engineering with an emphasis on hightemperature, high-performance materials. Awards are presented in conjunction with the Materials Science and Technology Conference and are funded by the TMS Foundation under the TMS International Symposium on Superalloys Committee.

\section{Adam Ladd \\ University of Illinois}

"It is a great honor to receive this scholarship! I have worked hard my entire academic career to be the best engineer and scientist that I could be, so it is nice to know that some of that hard work has paid off. This scholarship will help me leave college with less debt and allow me to start my future career on the right foot. Being a part of Material Advantage has been very impactful. I have made many friends, learned about different companies and career paths, and grown from a student to a professional. I cannot wait to make meaningful, world-changing contributions to society after I graduate."
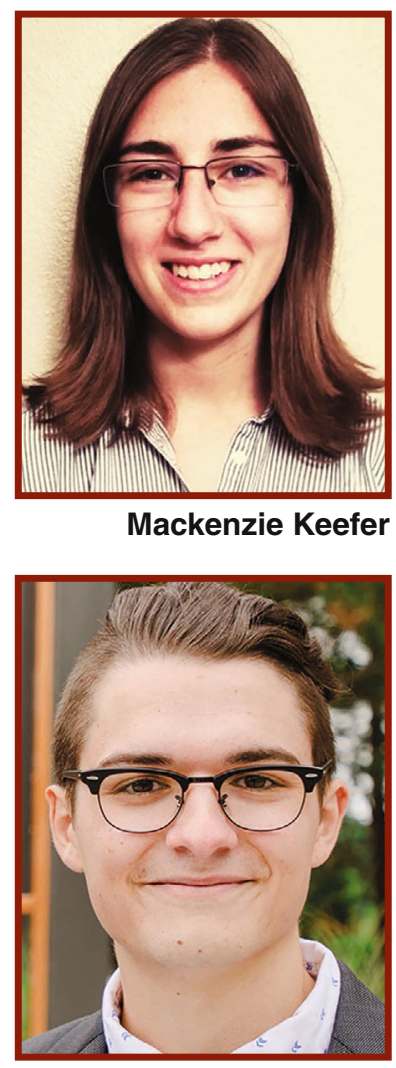

Matthew Thomas

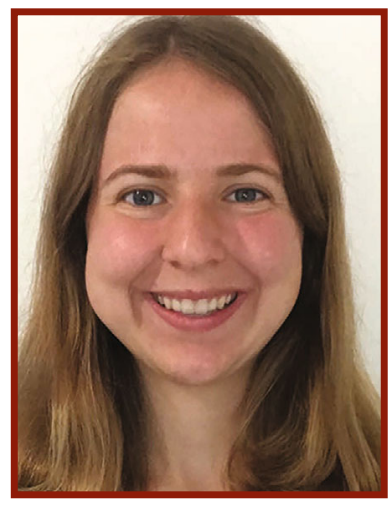

Katelyn Adkison

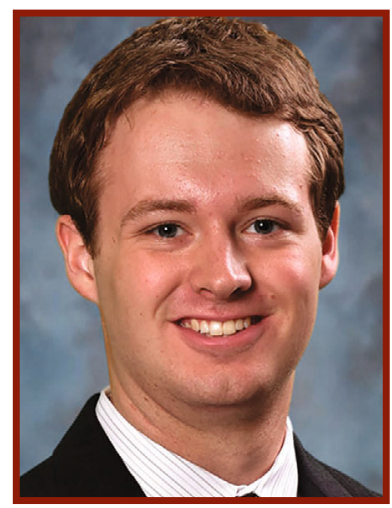

Adam Ladd 


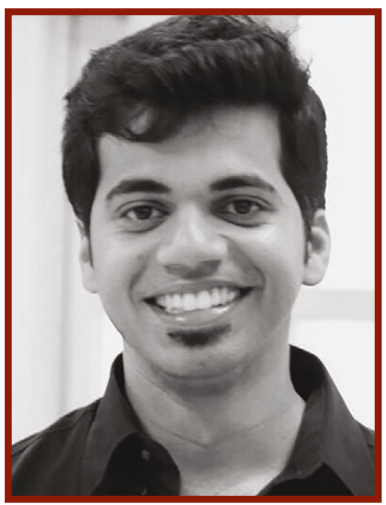

Hari Krishnan Rajendran

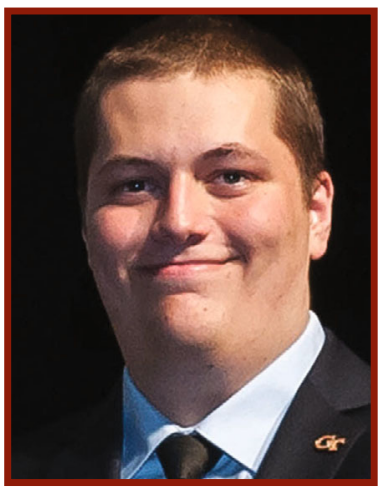

Keith Coffman

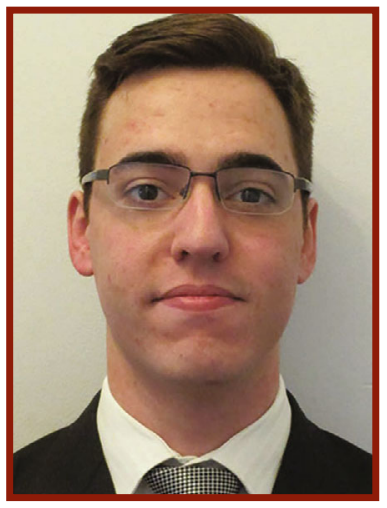

Rafael Rodriguez De Vecchis

\section{Hari Krishnan Rajendran}

Texas A\&M University

"I am incredibly humbled and honored to have been selected for this prestigious TMS scholarship. This recognition is an encouragement for my doctoral study which focuses on the fundamental understanding and prediction of the property degradation of Ni-based single crystal superalloys to better design the material for high-temperature applications, and thereby, retarding the insidious turbine blade failure. I would credit my advisor, Jean-Briac le Graverend, for instilling in me a passion for this line of research and motivating me to strive for better contributions to the field. I would also like to thank the TMS Foundation, the organizing committee of the International Symposium on Superalloys, and the Material Advantage student program for the motivation and opportunities they provide to young researchers like me."

\section{ACTA MATERIALIA UNDERGRADUATE SCHOLARSHIP}

Supported by the generosity of Acta Materialia Inc. and issued under the TMS Foundation, this scholarship is available to undergraduate students majoring in metallurgical engineering, materials science and engineering, or to undergraduate students with a significant interest in the materials area.

\section{Keith Coffman}

\section{Georgia Institute of Technology}

"The resources made available by TMS are extremely valuable as they compile information on current techniques and challenges in a field, keeping students and professionals up to speed. All in all, the resources and networking opportunities afforded by active membership in TMS have been extremely supportive of my educational and career goals. I am completing my final year as an undergraduate in materials science and engineering as well as physics at Georgia Institute of Technology. After graduating I intend to pursue a Ph.D. in materials science. I will focus on computation and multiscale simulation of material properties from first principles, and I hope to apply my skills to solve energy generation and storage challenges, among many others."

\section{Rafael Rodriguez De Vecchis}

\section{University of Pittsburgh}

"TMS and Material Advantage have provided me with both an excellent academic environment where I can share my passion for materials science with my fellow classmates and the muchneeded financial support that allows me to move my engineering career forward. All this support has encouraged me to keep pursuing my aspirations for graduate school. I plan to proceed with a Ph.D. program in materials science with the goal of becoming a professor who is strongly committed to improving teaching by inspiring students to reach their full potential and dreams, as well as developing new scientific and technological knowledge on new materials that can improve society and guarantee a sustainable future for the next generations in collaboration with industry."

\section{Ashley-Anne Bohnert is the TMS Outreach \& External Communications Lead. Carol Matty, TMS Marketing Assistant, provided editorial assistance for this article.}

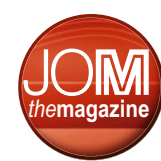

\section{Apply for a 2020 TMS Scholarship}

TMS scholarships provide financial assistance, early career recognition, and important opportunities for advancement through technical exchanges at the TMS Annual Meeting \& Exhibition.

If you are a full-time undergraduate or graduate student interested in assistance with tuition, consider applying for a 2020 TMS Scholarship before the deadline of March 15, 2019.

Applicants must submit a completed TMS scholarship application, three recommendations, a personal statement, and a transcript with current GPA to Bryn Simpson, TMS Membership and Volunteerism Program Manager, at bsimpson@tms.org. Some scholarship details have recently changed, so make sure to carefully review the award information at awards.tms.org.

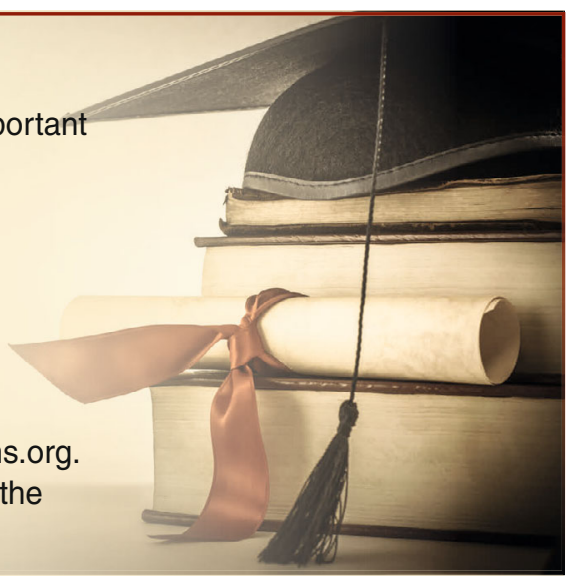

